\title{
Caleidoscopio del principio de la dignidad humana desde la jurisprudencia constitucional colombiana*
}

\section{Kaleidoscope of the human dignity principle from the Colombian constitutional jurisprudence perspective}

fecha de recepción: 14 de abril de 2011

Fecha de evaluación: 7 de junio de 2011 Fecha de aprobación: 21 de junio de 2011

\author{
Juan Pablo Romero Correa
}

\section{Resumen}

En los albores del neoconstitucionalismo, el derecho positivo quedó relegado al anacronismo que le impuso la puesta en práctica de los principios constitucionales. El Estado social de derecho, en el marco de la Constitución de 1991, va a encontrar en la exaltación de la dignidad de la persona humana el medio expedito para superar el rigorismo hermético de la ley, en procura de garantizar la realización de los contenidos axiológicos de la Carta. En este contexto se destaca la jurisprudencia de la Corte Constitucional de Colombia, corporación que logró traducir la forma monolítica de la ley a la diferente y compleja realidad social, consiguiendo que la irradiación de los principios constitucionales, y en concreto del de la dignidad humana se constituya en fundamento del intérprete y, de contera, en punto de referencia del ordenamiento jurídico.

Palabras clave: Dignidad humana, Estado social de derecho, principios constitucionales, persona humana, jurisprudencia constitucional, derecho constitucional

\footnotetext{
El presente artículo fue inspirado en una sección de la investigación intitulada: Éxodo campesino: el despojo de la dignidad, presentada para la obtención del título de Licenciatura en Filosofía de la Universidad Santo Tomás.

Abogado y Licenciado en Filosofía de la Universidad Santo Tomás. Miembro del grupo de Investigación Raimundo de Peñafort y docente de la Cátedra de Teoría del Estado de la Facultad de Derecho de la misma universidad.
} 


\begin{abstract}
At the dawn of neoconstitutionalism, positive law was relegated to the anachronism that gave him the implementation of constitutional principles. The Social State of Law within the framework of the Constitution of 1991, will find in the exaltation of the dignity of the human person, expeditious means to overcome the tight rigor of the law which seeks to ensure the realization of the ethical content of the Charter. In this context the jurisprudence of the Constitutional Court of Colombia stands out. It is a corporation that has managed to translate the monolithic form of law to the different and complex social reality, achieving that the irradiation of constitutional principles, specifically the principle of human dignity, would become a guide for the law.
\end{abstract}

Keywords: Human dignity, social state of law, constitutional principles, human, constitutional jurisprudence, constitutional law

\section{INTRODUCCIÓN}

La matriuska es una muñeca rusa que se encuentra hueca por dentro, de tal manera que en su interior alberga una nueva muñeca, la cual alberga otra, $y$ esta a su vez otra, y otra, en un número variable que puede ir desde cinco hasta el que se desee. La dependencia que subyace entre la dignidad y los derechos que devienen de ella encuentra en la matriuska una forma de expresión, de modo que en el interior de cada derecho emerge un correlativo contenido de dignidad que conduce a la realización de unas garantías mínimas orientadas a satisfacer las más elementales exigencias del ser humano. La Constitución de 1991 establece en el horizonte abierto de la dignidad humana el lugar por excelencia de los derechos, ella permite su visibilización; sin embargo, sin ella se convierten en simples enunciados teóricos ajenos a la persona humana; en virtud al principio de la dignidad humana, los derechos dejan de ser una entelequia para convertirse en una posibilidad de verdad para todos. En consecuencia, todos los derechos confluyen en un mismo eje articulador, la dignidad; responden a un mismo fin, la persona; y giran en torno a un mismo modelo, el Estado social de derecho.

\section{DIGNIDAD Y DIGNIFICACIÓN}

La palabra dignidad, del latín dignitas, forma abstracta del adjetivo dignus, hace relación a una cualidad sobresaliente o excelencia asociada a un estado adventicio de acción de la persona. El atributo dignidad es usado en relación con o con respecto a: digno de, apto para, merecedor de, superior a; lo cual explica por qué la idea de dignidad se articula a la de justicia y equidad. Santo Tomás hace eco de esta afinidad entre digno y justo en los siguientes términos: "lo que no es según la naturaleza, no es digno ni justo". Sin embargo, el término dignidad, más que proporción de igualdad implica relación de superioridad ora personal (eminencia del hombre sobre las demás cosas) o social (reconocimiento de un estatus político o religioso). El término dignificación, por su parte, está relacionado más estrechamente con el adjetivo digno. Es el resultado de hacer o hacerse digno de algo superior u obrar conforme a la propia condición o destino.

En consecuencia, al distinguir entre dignidad y dignificación, hacemos alusión a dimensiones específicas del ser humano. Una dignidad que corresponde al nivel ontológico en consonancia con el reconocimiento a la superioridad de la especie 
que otorga el atributo de la racionalidad, por el cual es posible abarcar y dominar la creación entera; $y$ una dignidad adquirida o adventicia relacionada con el ejercicio de un comportamiento personal o social. La dignidad, vista desde cualquiera de las dos perspectivas descritas, debe cumplir el precepto de Píndaro: "llega a ser lo que eres", y junto a Plotino, suscitar en el hombre una actitud de humanidad acorde con su naturaleza humana:

Entra en ti mismo y mira: si no ves todavía la belleza en ti, haz como el escultor que quiere hacer una hermosa estatua; quita materia, araña, pule, limpia. Como él, retira lo superfluo, rectifica lo que está torcido, limpia lo que está manchado a fin de conseguir tu propia brillantez, no ceses de esculpir tu propia estatua (Rodríguez, 1982: 9).

\section{SENTIDO Y ALCANCE DEL PRINCIPIO DE LA DIGNIDAD HUMANA EN EL MARCO DE LA JURISPRUDENCIA CONSTITUCIONAL}

La realización de la dignidad humana cumple un papel relevante en el contexto de la Constitución de 1991, al establecerse en el eje transversal para la interpretación de los preceptos constitucionales. En la Sentencia T-881 de 2002 se refirió la Corte a esta particular y determinó la naturaleza jurídica del derecho a la dignidad humana en el marco de la Carta Magna, así como las consecuencias normativas de su materialización en procura de realizar la fórmula del Estado social de derecho.

Con el fin de acatar las funciones que le impone la Constitución, la Corte Constitucional desarrolló el principio de la dignidad humana a partir de tres postulados, a saber:

1. La dignidad humana entendida en tanto que autonomía o posibilidad de las personas para construir su propia vida y realizarse como ser humano.
2. La dignidad comprendida desde la necesidad de satisfacer ciertas condiciones materiales de existencia.

3. La dignidad asociada a preservar la integridad física y moral de las personas ${ }^{1}$.

De acuerdo con las diferentes orientaciones jurisprudenciales que ha tomado la Corte, en la presente sentencia la dignidad se considera en su dimensión material, es decir, referida al goce $y$ disfrute de unas condiciones favorables de existencia que comuniquen al hombre vida digna. Si bien la expresión filosófica del término no es ajena a la pretensión de la Corte, su fundamentación se infiere de la decisión que se toma en la sentencia, dado que en principio la jurisprudencia no es el lugar para hacer disquisiciones dogmáticas, sino para aplicar el derecho a la vida práctica.

En tal sentido, a partir de la estructura funcional del término, esta corporación ofrece elementos de juicio para determinar los alcances del principio de la dignidad humana dentro de la Carta Política e identifica tres horizontes de comprensión:

- La dignidad humana entendida como principio fundante del ordenamiento jurídico y del Estado mismo, esto es, la dignidad como valor.

- La dignidad humana entendida como principio constitucional fundamental.

- La dignidad humana como derecho constitucional fundamental autónomo.

Debido a la abstracción del concepto, la Corte consideró que la dignidad humana no expresa una postura hermética e inmodificable. En este sentido, en uso de la eficacia del término, poco interesa que la misma se exprese como derecho fundamental, como principio constitucional o como valor; y del mismo modo, que sea expresión de la autonomía individual, de la expresión de ciertas condiciones materiales de existencia o

1 Corte Constitucional. Sentencia T-881 de 2002, m. p. doctor Eduardo Montealegre Lynett. 
como la manifestación de intangibilidad de ciertos bienes; siempre que se garantice su protección judicial, no importa tanto la denominación como sí su realización.

Desde la óptica del principio constitucional, la dignidad humana ha sido comprendida como:

\begin{abstract}
Un mandato constitucional, un deber positivo o un principio de acción, según el cual todas las autoridades del Estado, sin excepción, deben, en la medida de sus posibilidades jurídicas y materiales, realizar todas las conductas relacionadas con sus funciones constitucionales y legales con el propósito de lograr las condiciones para el desarrollo efectivo de los ámbitos de protección de la dignidad humana: autonomía individual, condiciones materiales de existencia, e integridad física y mora? (cursiva fuera del texto).
\end{abstract}

La dignidad humana, a partir de esta perspectiva, conmina al Estado a garantizar la protección de los derechos humanos no sólo como originalmente se entendieron, en el sentido de no interferir en el goce de los derechos de las personas, sino en la obligación de promover las acciones necesarias que conduzcan a que tales derechos puedan real y efectivamente ser ejercidos por las personas ${ }^{3}$, con lo cual se supera la simple retórica dentro de un universo de obstáculos institucionales o jurídicos y se establecen los fundamentos de la columna ética del Estado social de derecho.

Por otra parte, frente al reconocimiento de la dignidad humana como derecho constitucional fundamental, la Corte subrayó:

El derecho a la dignidad humana constituye un derecho fundamental autónomo y cuenta con los elementos de todo derecho: un titular claramente identificado, un objeto de protección más o me-

2 Corte Constitucional. Sentencia T-900 de 2005, m. p. doctor Alfredo Beltrán Sierra.

3 En internet: http://uww.scjn.gob.mx/2010/transparencia/Documents/ Becarios/Becarios_117.pdf. Consultado el 13 de abril de 2011. nos delimitado y un mecanismo judicial para su protección ${ }^{4}$. En este sentido, se consagra como un verdadero derecho subjetivo que posibilita la irradiación de los contenidos axiológicos de la Carta e influye definitivamente en la interpretación del ordenamiento jurídico. En definitiva, los ámbitos de protección de la dignidad humana deberán apreciarse no como contenidos abstractos sino como contenidos concretos, en relación con las circunstancias en las cuales el ser humano desarrolla su vida ordinariamente ${ }^{5}$.

En consecuencia, los diferentes predicados atribuidos a la dignidad humana sirven de fundamento al esqueleto jurídico del Estado social de derecho. Sin embargo, su consagración supera la simple expresión positiva; si bien ingresa allí por vía directa a través de la declaración constitucional, por vía indirecta permea todo el universo jurídico existente. Así pues,

[...] la operatividad del concepto pasa del plano prescriptivo al plano descriptivo, en este sentido la dignidad humana constituye un elemento definitorio del Estado social y de la democracia constitucional, existiendo entonces una suerte de relación conceptual NECESARIA entre dignidad humana y Estado social de derecho ${ }^{6}$ (negrita y mayúscula fuera del texto).

\section{DIFERENTES LÍNEAS DE INTERPRETACIÓN DEL PRINCIPIO DE LA DIGNIDAD HUMANA EN EL INTERIOR DE LA CORTE CONSTITUCIONAL}

Con respecto al nexo entre el principio de la dignidad humana y autonomía individual7 , la Corte ha señalado un estrecho vínculo con la libertad gene-

4 Corte Constitucional. Sentencia T-410 de 2003, m. p. doctor Jaime Córdoba Triviño.

5 Corte Constitucional. Sentencia C-397 de 2006, m. p. doctor Jaime Araújo Rentería.

6 Corte Constitucional. Sentencia T-488 de 2007, m. p. doctor Humberto Antonio Sierra Porto.

7 Consultar, entre otras: Corte Constitucional. Sentencias T-532 de 1992; T-542 de 1993; T-477 de 1995; T-239 de 1997. 
ral de acción, esto es, entre la dignidad humana y la capacidad de orientar la vida hacia la consecución de unos fines que contribuyan al crecimiento de la persona en todas sus dimensiones. La libertad no se entiende aquí desde la herencia de la conciencia moderna, sino como una libertad responsable que aporta desde la individualidad. El ser social se comprende desde la perspectiva de la realización de los fines sociales en los cuales el ejercicio de la autonomía personal aporta a la construcción social.

Por otra parte, la Corte establece la conexión entre el principio de la dignidad humana y la necesidad de asegurar unas condiciones materiales de existencia que permitan construir calidad de vida. Con ello la Corte no pretende el acceso a bienes suntuarios o lujosos, sino al disfrute de aquellos bienes indispensables para sobrellevar una vida en condiciones de dignidad. En consecuencia, la garantía de la dignidad humana implica deber correlativo por parte del Estado y de las autoridades públicas en orden a realizar el derecho al mínimo vital, mediante la práctica de efectivas políticas públicas que conduzcan, de contera, a la vigencia del Estado social de derecho ${ }^{8}$.

Finalmente, la Corte establece los linderos para la comprensión de la dignidad humana en el marco del respeto a la integridad física y psíquica de las personas; promueve el derecho que tiene todo ser humano a vivir libre de humillaciones, marginado, sometido a tratos crueles, inhumanos o degradantes. Como respuesta a su función de garante de la Norma superior, define un margen de acción para la protección de los "invisibles" ${ }^{9}$, con lo cual logra marcar una pauta para la justiciabilidad de los derechos por parte del Estado en el ordenamiento jurídico ${ }^{10}$.

8 Consultar, entre otras: Corte Constitucional. Sentencias T-596 de 1992; T-296 de 1998.

9 Término acuñado por Fajardo Sánchez, L., Abondano Lozano, D., (2006), en el libro Los invisibles y la lucha por el derecho en Colombia, Ed. USTA, Bogotá.

10 Consultar, entre otras: Corte Constitucional. Sentencias T-401 de 1992; T-402 de 1992; T-123 de 1994; T-036 de 1995; T-645 de 1996;

\section{PROTECCIÓN DEL CONTENIDO MATERIAL DE LOS DERECHOS A PARTIR DEL PRINCIPIO DE LA DIGNIDAD HUMANA}

Existe una relación tácita, dentro de la configuración de nuestra Carta Política, que origina una interpretación de los derechos a la luz de los principios constitucionales; el principio de la dignidad humana extiende sus raíces en el horizonte de tal comprensión y atraviesa transversalmente toda la Constitución, contaminando las diferentes formas de expresión legal existente en la actualidad; de este modo, es dable calificar ciertos eventos de la vida social con el estigma de la dignidad, verbi gratia: vida digna, muerte digna, salario digno, trabajo digno e, incluso, tierra digna o dignidad de la tierra.

La jurisprudencia de la Corte ha abordado tres enfoques diferentes y más o menos delimitados frente al término: la dignidad humana como autonomía individual, como condiciones de existencia y como intangibilidad de ciertos bienes.

\section{Primer enfoque: la dignidad humana y la autonomía individual}

La jurisprudencia de la Corte Constitucional ha hecho efectiva la protección de derechos de diversa índole contenidos en la Carta Magna; sus decisiones generan una conexión entre derechos y dignidad, cuya intimidad permea incluso el ejercicio de la administración de justicia al someter la interpretación de las normas al prisma constitucional en orden a satisfacer la justicia material. En tal sentido, en la Sentencia T-532 de 1992, esta corporación estableció la estrecha relación entre la libertad individual y la dignidad humana. En la Sentencia C-542 de 1993, la Corte recurrió al imperativo categórico de Kant para fortalecer la idea según la cual el interés colectivo debe ceder a los derechos fundamentales cuando están en juego

T-572 de 1999; T-879 de 2001. 
Ios que comprometan la libertad o la vida, inherentes a la dignidad del ser humano. En el mismo sentido, se insistión ${ }^{11}$ en que la dignidad se obtiene con el pleno ejercicio de la libertad individual. En la Sentencia C-239 de 1997, la Corte estableció un eximente de responsabilidad frente al homicidio por piedad bajo el presupuesto de la dignidad entendida como la facultad del enfermo para decidir sobre su vida en determinadas circunstancias. En la Sentencia T-461 de 1998, la Corte consideró que la práctica conducente a restringir el acceso del trabajador al sitio de trabajo se orienta a configurar el despido indirecto y afecta la dignidad humana en tanto imposibilita al trabajador el despliegue de las actividades contratadas.

\section{Segundo enfoque: la dignidad humana y las condiciones materiales de existencia}

En la Sentencia T-596 de 1992 se ordenó realizar la reparación de algunos sectores de un centro penitenciario a raíz de la acción de tutela instaurada por un interno que debía soportar los malos olores que despedían unas letrinas abiertas ubicadas cerca de su lugar de descanso. En el presente caso, la Corte consideró que la dignidad opera como calificativo $^{12}$ de la forma de vida, de modo que el enunciado vida digna está íntimamente relaciona-

11 La Corte Constitucional en la Sentencia C-542 de 1993 señaló: "La verdadera libertad es signo del señorío del hombre sobre las contingencias de la vida, de suerte que la razón hace que el ser humano esté en manos de su propia decisión, y por eso es responsable, según se expresó. La dignidad humana requiere que el hombre actúe según su recta razón y libre elección, movido por la convicción interna personal y no bajo la presión que otros hagan sobre su libertad, porque entonces el acto no sería libre, y al no serlo, no puede estar amparado por la legitimidad. El hombre, pues, logra la dignidad cuando se libera totalmente de toda cautividad y cuando pone los medios para que sus semejantes no caigan en dicho estado indigno".

12 Corte Constitucional. Sentencia T-322 de 2007. "El Estado colombiano se funda en el valor de la dignidad humana, lo cual determina, no sólo un deber negativo de no intromisión sino también un deber positivo de protección y mantenimiento de condiciones de vida digna. Las personas recluidas en establecimientos carcelarios se encuentran bajo la guardia del Estado. Ello implica, por un lado, responsabilidades relativas a la seguridad de los reclusos y a su conminación bajo el perímetro carcelario y, por el otro, responsabilidades en relación con las condiciones de vida de los reclusos". do con el goce y disfrute de ciertas condiciones materiales de existencia. En la Sentencia T-124 de 1993, la Corte garantizó el derecho de petición de una persona de la tercera edad que requería el reconocimiento de la pensión; para el efecto, estableció la conexión entre la igualdad material, las condiciones materiales de vida y la dignidad. En la Sentencia T-556 de 1998, la Corte garantizó el derecho a la salud en conexión con el derecho a la vida digna de una menor que necesitaba silla de ruedas bajo el presupuesto de que las condiciones materiales de existencia superan la pretensión económica propiamente dicha, siendo por tanto imperativo exaltar a la persona como fin y no como medio, y en tal sentido la ausencia de recursos económicos no es óbice para desconocer el acceso a los derechos por parte de las personas.

\section{Tercer enfoque: la dignidad humana y la intangibilidad de los bienes no patrimoniales, integridad física $\mathrm{e}$ integridad moral}

En la Sentencia T-401 de 1992, la Corte decide acerca de la protección del derecho a la integridad moral de unos reclusos declarados inimputables por demencia, cuya medida de seguridad consistente en internación psiquiátrica se había prolongado indefinidamente, lo cual constituía una pena o trato cruel, inhumano o degradante. La dignidad humana fue transgredida en el caso sub júdice, desconociendo que toda persona, en razón de su condición humana, goza de igual consideración y respeto, y debe reconocérsele la capacidad de autodeterminación y la posibilidad de gozar de los bienes inapreciables de la existencia ${ }^{13}$. Por otra parte, la Sentencia T-402 de 1992 tuteló el derecho a la integridad moral de un menor a quien su profesora castigó con un esparadrapo en la boca. En el presente caso, la humillación padecida por el menor constituye una práctica lesiva de la dignidad humana, con capacidad de poner en peligro su

13 Corte Constitucional. Sentencia T-401 de 1992, m. p. doctor Eduardo Cifuentes Muñoz. 
desarrollo mental, toda vez que el castigo infligido degrada a la persona al generar pérdida de autoestima o incluso trastornos de personalidad. En la Sentencia T-036 de 1995, la Corte fijó los parámetros de comprensión de la dignidad humana en el campo de los derechos fundamentales, en conexión con el derecho a la integridad física. En consecuencia, prohíbe la realización de trabajos forzados y tutela el derecho de los tutelantes a la integridad física como una prolongación del derecho a la vida, el cual halla fundamento en el principio de la dignidad humana.

\section{CONSIDERACIONES FINALES}

En definitiva, la dignidad de la persona se origina en la incontrovertible condición de separación, especificidad, sacralidad y principio fundante de la naturaleza, según la cual el ser humano es único en relación con los demás seres vivos, está dotado de racionalidad como atributo propio y diferencial, y existe por sí mismo sin menoscabo de ninguno, con posibilidad de autodeterminarse e imponerse sus propios límites y posibilidades: el ser humano es expresión de libertad. Comparte el ser con todo, pero es superior a todo en cuanto domina y somete cuanto existe, participa del ser de los minerales, los animales y los vegetales, pero los tiene a su servicio. El ser humano subsiste por sí mismo, tiene autonomía y, por lo tanto, excluye que se lo convierta en medio para lograr fines; en conclusión, según el sentir de Kant, la persona es "un fin en sí misma".

Por lo demás, el concepto de dignidad acogido por nuestra Constitución articula el ideal democrático que subyace al modelo del Estado social de derecho, cuyo eje dinamizador es la persona humana; por lo tanto, descarta toda actitud que contradiga la realización del ser humano en todas sus dimensiones y garantiza la promoción de sus derechos y necesidades más apremiantes, pues reconoce en él la razón de su existencia y la base y justificación de todo el sistema institucional y legal. En consecuencia, no se garantiza ningún derecho si a un individuo de la especie se lo condena a sobrevivir en condiciones inferiores a las que la naturaleza le señale en cuanto ser humano; es decir, cuando se imponen intereses diferentes a los que la Constitución consagra como superiores, en claro menoscabo del amparo debido que se reconoce a toda persona.

Así las cosas, el enfoque garantista que se le dio al principio de la dignidad humana no responde a una muletilla de fina retórica que utiliza la Corte Constitucional para hacer eco de una línea humanista tendenciosa o simulada; en su lugar, hace parte del desarrollo de un nuevo modelo de derecho heredado de la Carta Magna de 1991, en el cual la simple enunciación de normas sujetas a la voluntad del legislador se somete a la "omnipresencia de la Constitución" (Figueroa, 2005: 165). El sustrato axiológico se constituye así en puente comunicante entre la opción legislativa o reglamentaria y la realidad social, de suerte que se atiende a los principios y valores contenidos en la Norma Superior como horizonte de comprensión del ordenamiento jurídico; en este sentido, el derecho positivo emerge del cuerpo vital de la Constitución con un rostro cercano a la realidad humana.

\section{REFERENCIAS}

Figueroa García, A. (2005). La teoría del derecho en tiempos de constitucionalismo. En Carbonell, M. Neoconstitucionalismo (s). México: Ed. Trotta.

Rodríguez, V. (1982). La dignidad del hombre como persona. En Dignidad de la persona y derechos humanos. Madrid: Instituto Pontificio de Filosofía. 